\title{
NUTRIÇÃO MINERAL DE PLANTAS ORNAMENTAIS. VI. EFEITOS DE PARCELAMENTO DE ADUBAÇÃO NITROGENADA E POTÁSSICA NA CULTURA DE Gladiolus grandiflorus L., cv. "Friendship'
}

\author{
Pedro Dantas Fernandes ** \\ Henrique Paulo HaAg \\ SaLIM Simáo \\ Jairo Ribeiro de Mattos
}

\begin{abstract}
RESUMO
Efeitos de parcelamento de adubação nitrogenada e potássica foram estudados na cultura de Gladiolus grandiflorus, L., cr. 'Friendship', no que concerne a produção de bulbos, bulbilhos e hastes florais.

Houve influência do parcelamento sobre número e peso de bulbos e bulbilhos e sobre comprimento de haste floral do gladiolo. Fim geral o nitrogênio influiu sobre número de bulbos e de bulbilhos, enquanto o potássio influenciou em seu peso.
\end{abstract}

\section{INTRODUCAAO}

Apesar da grande importânncia que vem tendo a cultura de gladíolos em nosso país (MIRANDA, 1970) só ultimamente vem sendo conduzidos ensaics visando sua nutrição mineral em nossas condições (HAAG et al, 1970; FERNANDES, 1974; PUCCINELLI \& FERNANDES, 1974).

Como tem sido registrado em outros países (VAN DIEST \& FLANNE. RY, 1963) também aqui vem sendo verificadas respostas diferentes à adubação, de acordo com o cultivar utilizado, tipo de solo e tamanho de bulbo plantado.

- Entregue para publicação em 30/12/1974.

* Departamento de Fitotecnia, F. M. V. A. Jaboticabal - SP.

** Departamento de Química, E. S. A. «Luiz de Queiroz» - USP

***: Departamento de Agricultura e Horticultura, E. S. A. «Luiz de Quelroz» - USP. 
Segundo HAAG et al. (1970) e FERNANDES (1974), potássio e nitrogênio são elementos requeridos em maior quantidade pelo gladíolo, ocorrendo extração máxima respectivamente aos 45 e 75 dias de idade. De acordo com a literatura consultada, entre os nutrientes as maiores respostas tem sido obtidas para adubação nitrogenada e potássica (KENNETH, 1950; KRONE, 1951; WOLTZ, 1955, 1959, DIEGO, 1973).

0 objetivo do presente trabalho foi estudar os efeitos de adubação nitrogenada e potássica em cobertura, feitas em épocas diferentes, sobre produção de bulbos, bulbilhos e de hastes florais.

\section{MATERIAL E MÉTODOS}

O experimento foi conduzido em condições de Jaboticabal - SP, em solo pertencente ao Grande Grupo Latossol Vermelho-escuro fase Arenosa, cuja análise química realizada segundo CATANI et al. (1955) está exposta no Quadro 1.

QUADRO 1 - Características químicas do solo em que foi instalado o presente ensaio.

\begin{tabular}{|c|c|c|c|c|c|}
\hline $\mathrm{pH}$ & $\% \mathrm{C}$ & \multicolumn{4}{|c|}{ Teor em miliequivalentes $/ 100 \mathrm{~g}$. solo } \\
\hline 5,9 & 2,85 & $\begin{array}{l}{ }^{*} \mathrm{PO}_{4}-3 \\
0,16\end{array}$ & $\begin{array}{l}\mathrm{K}+ \\
0,13\end{array}$ & $\begin{array}{c}\mathrm{Ca}+\mathrm{Mg} \\
3,00\end{array}$ & $\begin{array}{r}\mathrm{A1}^{-3} \\
0,08\end{array}$ \\
\hline
\end{tabular}

* - solúvel $\mathrm{em}_{2} \mathrm{SO}_{4}-0,05 \mathrm{~N}$

O cultivar utilizado foi 'Friendship' de Gladiolus grandiflorus L., através de bulbos com aproximadamente $3,5 \mathrm{~cm}$ de diâmetro (N. ${ }^{0} 2$, segundo SOUZA, (1959). Após preparo do solo, foram abertos sulcos a distâncias de $0,60 \mathrm{~m}$ e profundidade de $0,25 \mathrm{~m}$. Antes do plantio houve adubação no fundo dos sulcos em todas as parcelas, seguindo recomendações de FERNANDES (1972), nas seguintes doses por metro linear de sulco: $15 \mathrm{~g}$. de sulfato de amônio, $45 \mathrm{~g}$. de superfosfato simples e $10 \mathrm{~g}$ de cloreto de potássio.

Tratamentos:

Foi estudado o parcelamento de adubação nitrogenada e potássica em diferentes épocas. Epocas $-\mathrm{E}_{1}$ : aplicado aos 30 dias após brotação dos bulbos; E2: aplicado aos 45 dias após brotação; $\mathrm{E}^{3}$ : aos 30 e 45 dias após brotação dos bulbos. Adubação em cobertura - $\mathrm{A}_{2}: 6 \mathrm{~g}$. de $\mathrm{N}$ na forma de sulfato de amônio por metro linear de fileira de plantas; $\mathrm{A}_{2}: 12 \mathrm{~g}$. de $\mathrm{K}_{2} \mathrm{O}$, como cloreto de potássio, por metro linear; $\mathrm{A}_{3}: 6 \mathrm{~g}$. de $\mathrm{N}$ mais $12 \mathrm{~g}$. de $\mathrm{K}_{2} \mathrm{O}$, sob as formas dos respectivos adubos, por metro linear de fileira de plantas. Nos tratamentos em que constava a época $E_{3}$, as doses foram divi- 
didas para as duas datas de aplicação. As aplicações em cobertura foram em faixas de $20 \mathrm{~cm}$ de um lado da fileira de plantas.

Ao todo foram portanto nove tratamentos, sendo acrescentado mais um tratamento como testemunha ( $\mathrm{T}$ ), em que houve adubação apenas no plantio, sem nenhuma cobertura posterior.

As parcelas tinham dimensões de $2,40 \times 0,80 \mathrm{~m}$, sendo quatro fileiras de $0,80 \mathrm{~m}$ de comprimento espaçadas de $0,60 \mathrm{~m}$, num total de 40 bulbos/ parcela, considerando-se seis bulbos úteis no centro da área.

Para coleta de dados as hastes florais foram colhidas quando apresentavam o primeiro botão se abrindo, obtendo-se seu comprimento da base da planta à extremidade da haste; colheram-se os bulbos e bulbilhos 40 dias após o corte das hastes florais, processando-se a sua contagem e pesagem.

Utilizou-se de blocos casualizados, com três repetições, Teste $\mathbf{F}$ e Teste Tukey a $5 \%$ de probabilidade (PIMENTEL GOMES, 1970).

\section{RESULTADOS E DISCUSSAOO}

Numero de bulbos e de bulbilhos

0 Quadro 2 apresenta os valores de Teste F (5\%) obtidos da análise de número de bulbos e número de bulbilhos.

QUADRO 2 - Valores de Teste $F(5 \%)$ da análise de número de bulbos e número de bulbilhos.

\begin{tabular}{lcc}
\hline Variação & Número de bulbos & Número de bulbilhos \\
\hline T (testemunha) & 1,82 & 0,77 \\
E (Epocas) & $5,33^{*}$ & 2,03 \\
A (Adubação) & $10,50^{*}$ & 2,49 \\
E x A & $17,25^{*}$ & $5,85^{*}$ \\
\hline
\end{tabular}

C. V. $(\%) \quad 8,08$

* - significativo ao nível de $5 \%$.

Feito desdobramento da interação E x A significativa, são apresentadas na Figural as médias do número de bulbos obtidos, bem como os valores de diferença mínima significativa (d. m. s., Tukey $5 \%$ ), para os vários tramentos.

Observa-se que todos os tratamentos de adubação em cobertura, quer nitrogenada ou potássica, apresentaram melhor efeito que a testemunha (T), onde houve aplicação de fertilizantes apenas no plantio. As melhores respostas foram obtidas com nitrogênio, quando aplicado aos 45 dias ou 
aos 30 e 45 dias após brotação dos bulbos. 0 efeito do potássio foi maior quando aplicado também com nitrogênio aos 30 e 45 dias de idade das plantas. Estas datas coincidem, segundo HAAG et al. (1970) com o início de formação de bulbos.

Maior influência de nitrogênio sobre número de bulbos foi também observada por VAN DIEST \& FLANNERY (1963) e por FERNANDES (1974).

Com relação ao número de bulbilhos obtidos, a interação significativa encontrada no Quadro 2 foi desdobrada, apresentando-se na Figura 2 as médias obtidas para os vários tratamentos. Verifica-se que maior número de bulbilhos são obtidos com aplicação de $\mathrm{N}$ e $\mathrm{K}$ aos 45 dias ou aos 30 e 45 dias de idade das plantas. De acordo com WATERS (1965) a produção de bulbilhos é mais beneficiada com adubação nitrogenada que potássica, não havendo referência a épocas de aplicação.

Peso da matéria fresca de bulbo e de bulbilho

Os valores do Teste $F(5 \%)$ para peso médio da matéria fresca de bulbo e peso médio de bulbilho, estão contidos no Quadro 3.

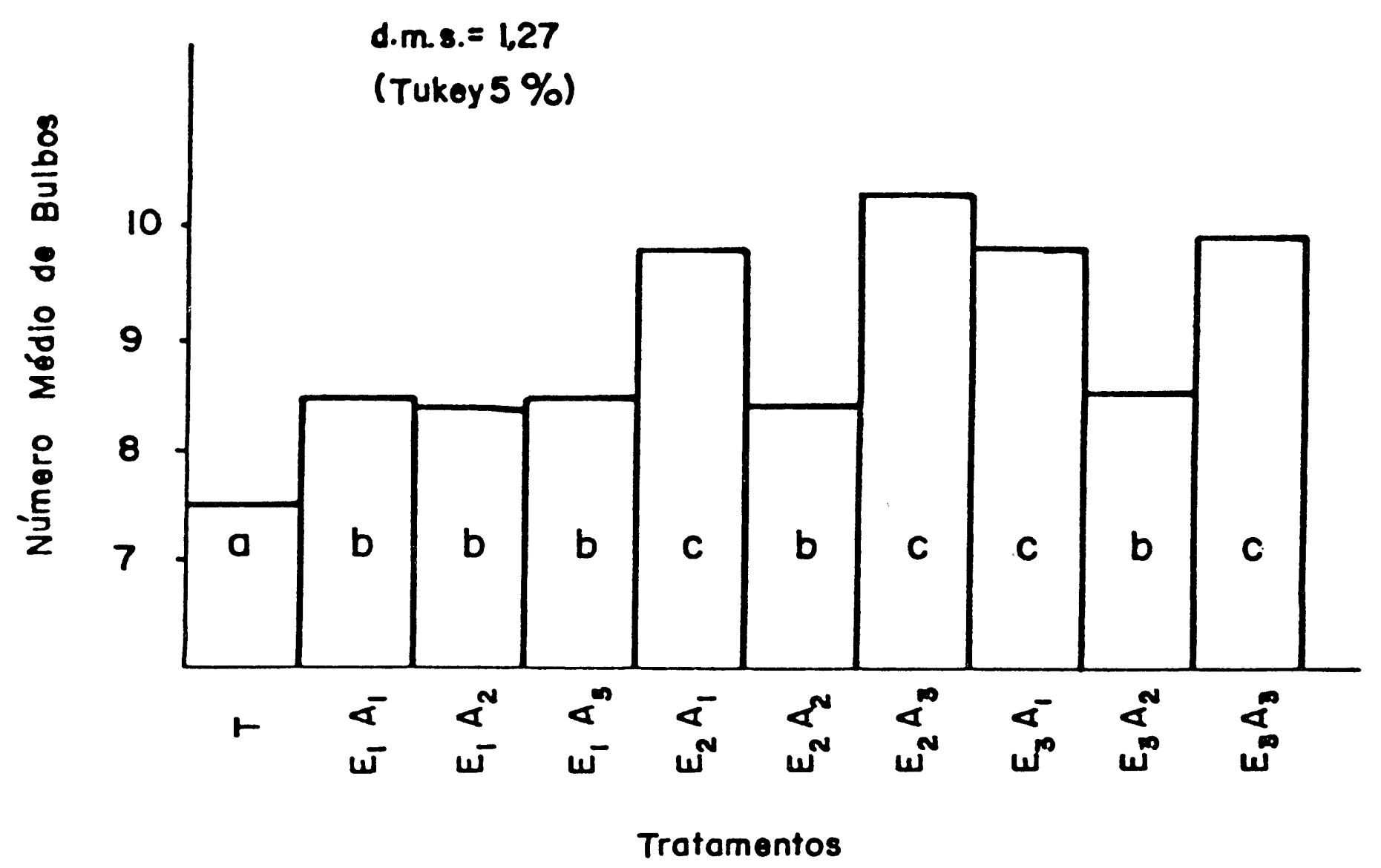

Figura 1: Número mẻdio de bulbos obtidos por parce la, segundo os tratamentos (colunas con tendo mesma letra não diferem entre si). 


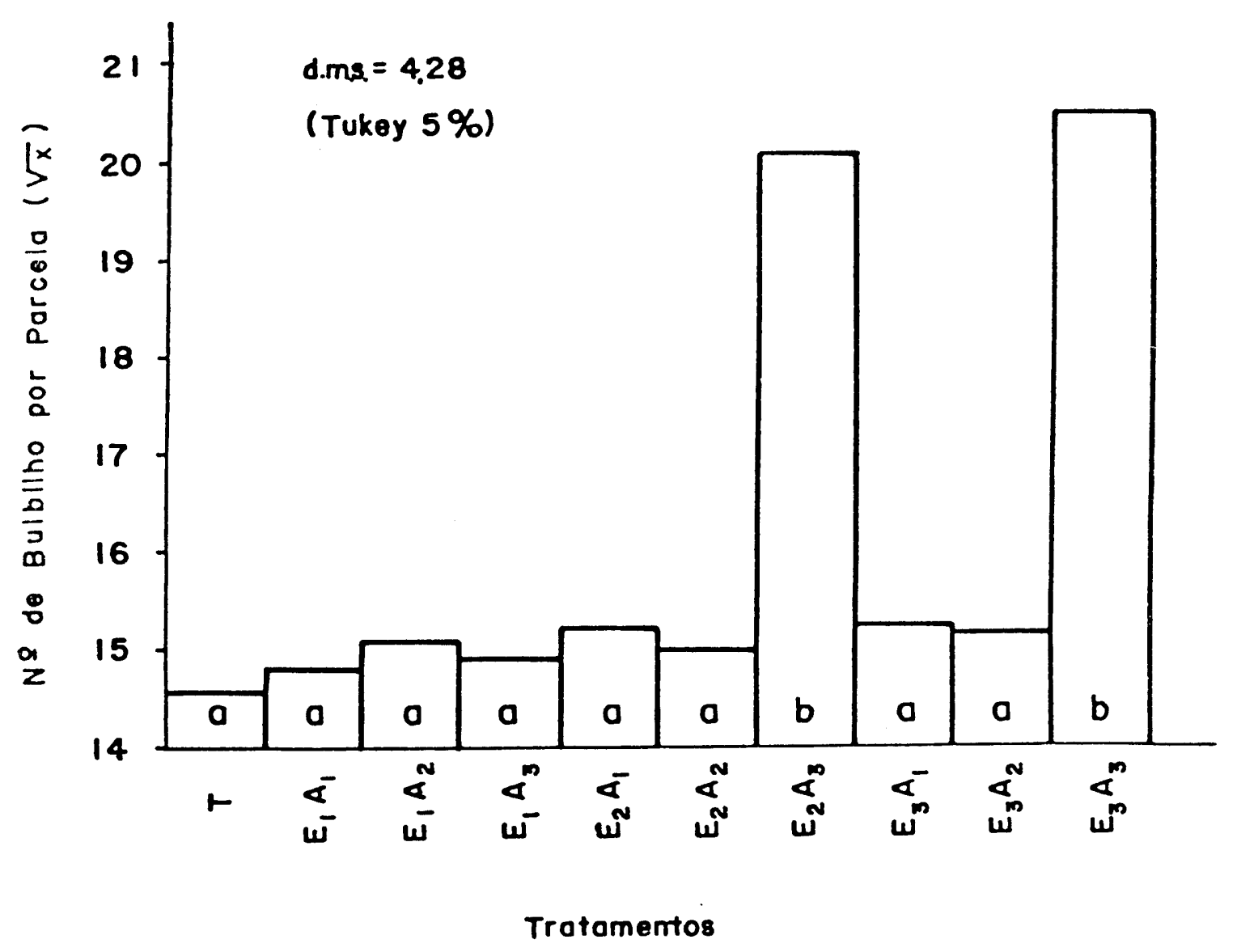

Figura 2: Nümero médio de bulbilhos $(\sqrt{x})$ obtidos nos värios tratamentos. (colunas contendo mesma letra não diferem entre si).

QUADRO 3 - Valores de Teste F (5\%) para peso médio de bulbo e de bulbilho.

\begin{tabular}{lcc}
\hline Variação & Peso médio de bulbo & Peso médio de bulbilho \\
\hline T (testemunha) & 1,41 & 0,59 \\
E (épocas) & $4,08^{*}$ & 1,38 \\
A (adubação) & $5,86^{*}$ & $4,59^{*}$ \\
E x A & $8,04^{*}$ & 2,68 \\
\hline C. V. $(\%)$ & 10,21 & 11,58 \\
\hline
\end{tabular}

* - significativo ao nível de $5 \%$. 
Verificada significativa a interação $\mathrm{E} \times \mathrm{A}$ para peso médio de bulbo, fez-se o seu desdobramento, apresentando-se na Figura 3 as respectivas médias para os vários tratamentos.

Inicialmente verifica-se que independente das épocas de aplicação, a adubação em cobertura de nitrogênio não mostrou influência sobre o peso médio de bulbo. Entretanto aplicações de potássio proporcionaram a obtenção de bulbos mais pesados, o que vem de acordo às informações da literatura de sua influência sobre a translocação de açúcares para raízes, bulbos e tubérculos, armazenando-se como substâncias de reserva (MALAVOLTA et al. 1955; ULRICH \& OHKI, 1966). Maior peso de bulbos foi também encontrado por FERNANDES (1974) com adubação potássica.

Ainda em relação à Figura 3, observa-se que o efeito do potássio foi maior com aplicação aos 45 dias de idade das plantas, quando segundo HAAG et al. (1970), começa a haver um grande acréscimo em sua extração.

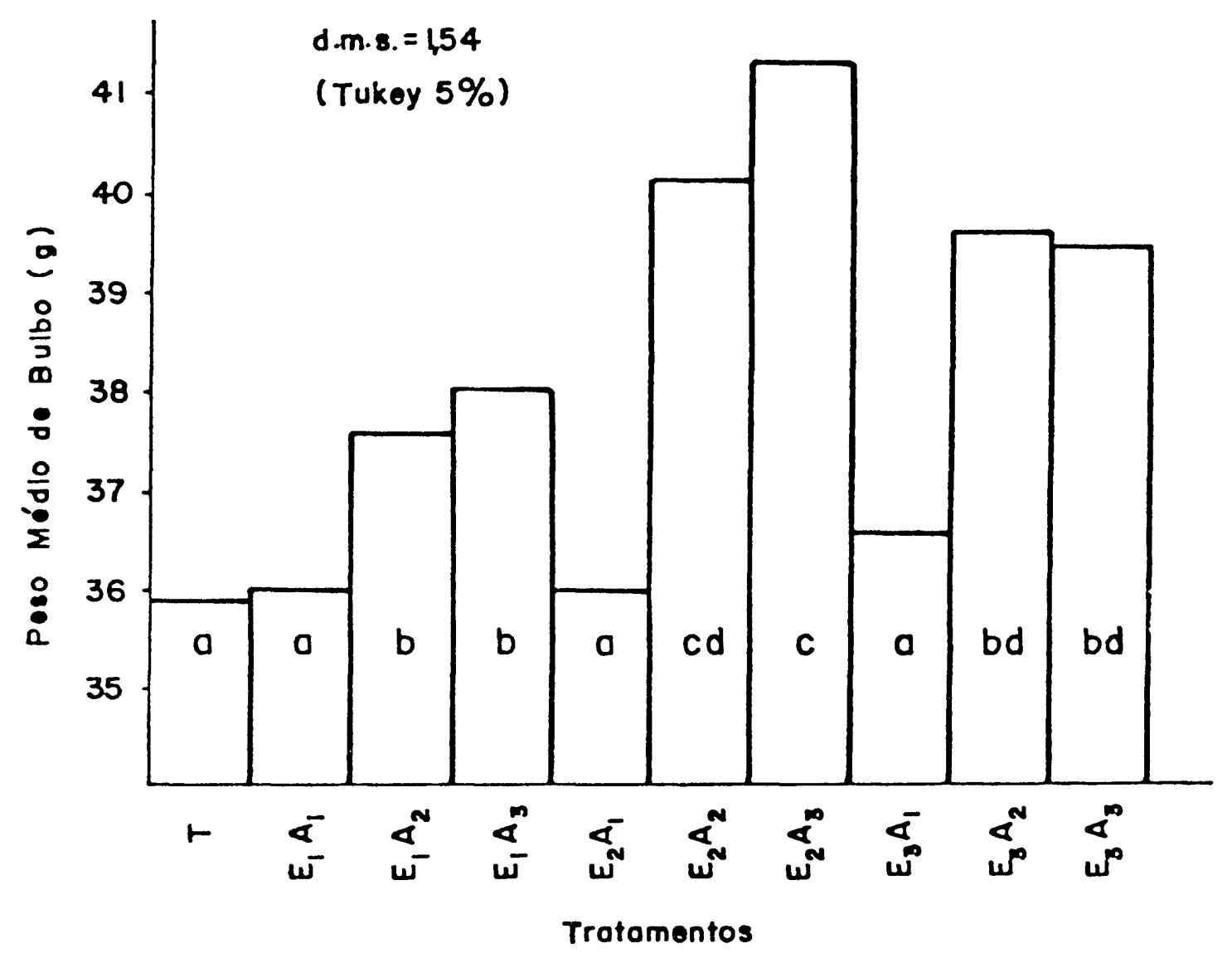

FIG. 3 - Peso médio de bulbo (g) obtido nos vários tratamentos. (Colunas contendo a mesma letra não diferem entre si).

Quanto a peso de bulbilho tendo sido significativo apenas A (Adubação), através da Figura 4 observa-se que, independente da época em que houve aplicação de fertilizantes, potássio mostrou-se também respon-

Parte aérea

No Quadro 4 são expostos os valores de Teste F (5\%) dos dados obtisável por bulbilhos mais pesados. 
QUADRO 4 - Valores de Testes F (5\%) para comprimento de haste e número de botões florais por haste.

\begin{tabular}{lcc}
\hline \hline Variação & Comprimento de haste & Número de botões/haste \\
\hline T (testemunha) & 0,62 & 1,05 \\
E (épocas) & 1,22 & 2,03 \\
A (Adubação) & $5,05^{*}$ & 1,89 \\
E x A & 2,33 & 2,38 \\
\hline C. V. $(\%)$ & 6,50 & 12,25 \\
\hline
\end{tabular}

* - significativo ao nível de $5 \%$.

Na Figura 5 estão contidas as médias de comprimento de haste floral obtidas para a testemunha e para os tratamentos de Epocas e Adubação. Observa-se que a adubação em cobertura teve efeito sobre o comprimento de haste floral, apenas quando houve aplicação de nitrogênio e de potássio juntos, independente da época em que foram aplicados.

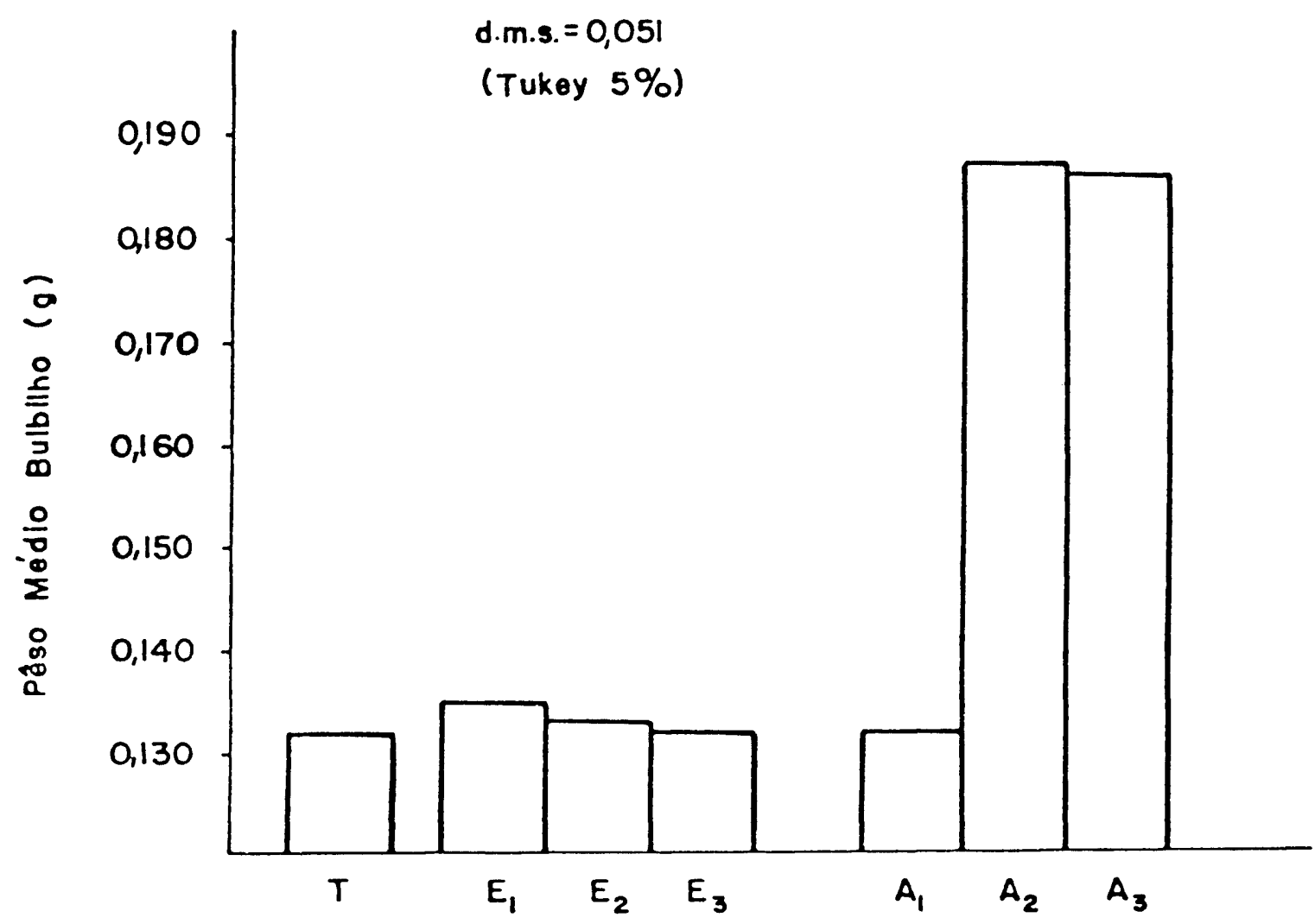

Figura 4: Peso médio de bulbilho (g) obtido segun do as épocas de Aplicação (E) e o adubo utilizado (A). 


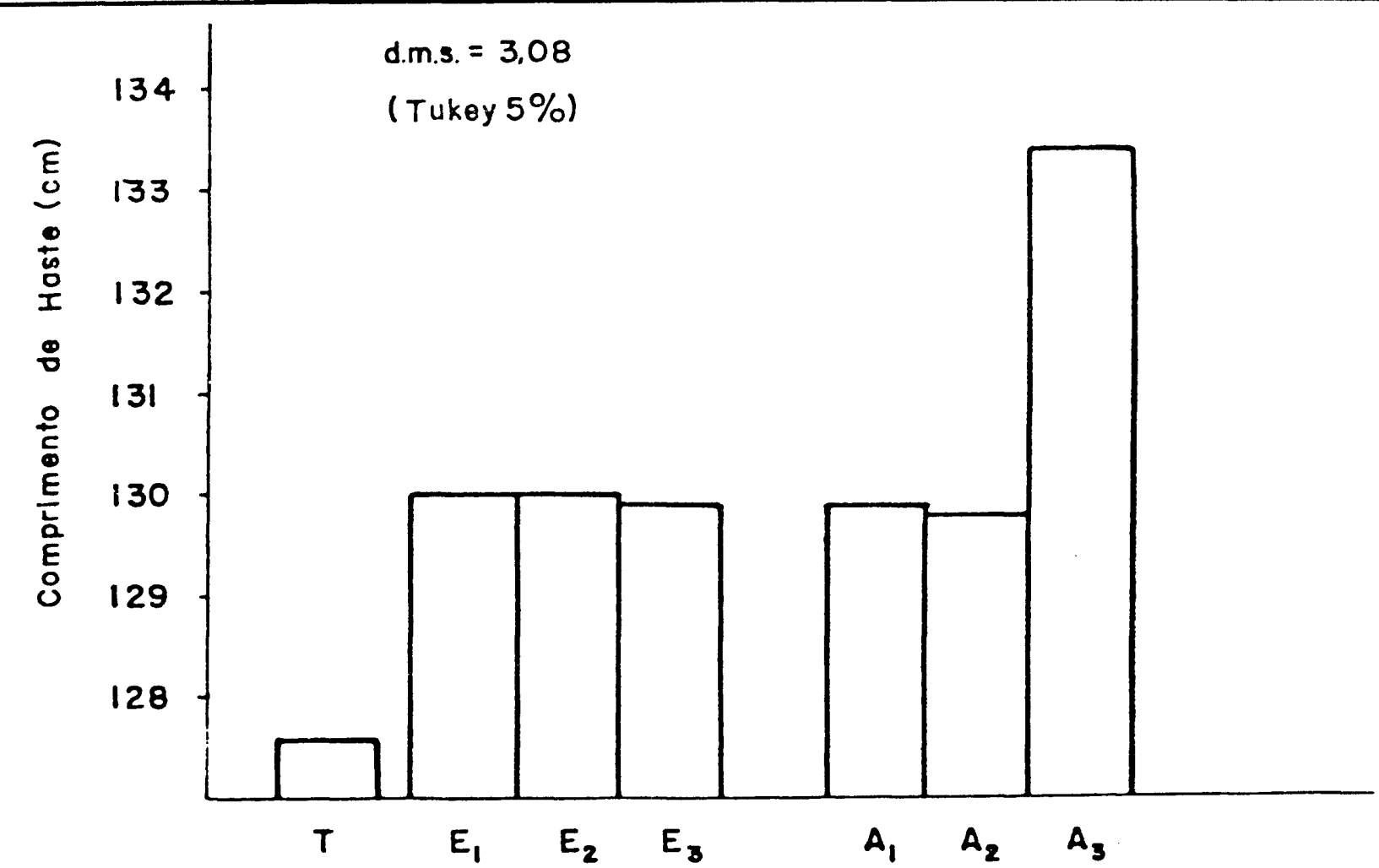

Figura 5: Comprimento mëdio de haste floral $(\mathrm{cm})$

$$
\begin{aligned}
& \text { obtida na Testemunha }(T) \text { e segundo as } \\
& \text { épocas (E) e adubo utilizado (A). }
\end{aligned}
$$

Em referência ao número de botões florais por haste, verifica-se através do Quadro 4 e Figura 6 que nenhum dos tratamentos apresentam influência, apesar de ter havido ef eito no comprimento de haste.

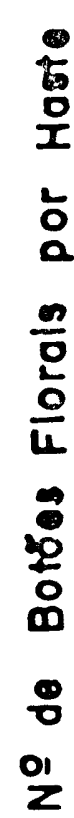

$$
\text { d.m.8. }=2,05
$$

(Tukey 5\%)

18

$-1$ 


\section{CONCLUSOES}

a) - Há efeito de parcelamento de adubação nitrogenada e potássica sobre número e peso de bulbos e bulbilhos e sobre comprimento de haste floral de gladiolo;

b) - para obtenção de maior número de bulbos recomenda-se aplicar nitrogênio aos 45 dias de idade das plantas;

c) - nitrogênio mais potássio aos 30 e 45 dias influi no maior número de bulbilhos;

d) - bulbos mais pesados são obtidos com potássio ou com potássio mais nitrogênio, aplicados as 45 dias de idade das plantas;

e) - cobertura com adubo nitrogenado e potássico resulta em hastes florais mais compridas.

\section{SUMMARY}

MINERAL NUTRITION OF ORNAMENTAL PLANTS. VI EFFECTS OF PARCELLING NITROGEN AND POTASSIC FERTILIZATION.

The presente experiments had as it objectives the cultivation of Gladiolus grandiflorus, L., cv. 'Friendship', in field conditions, studying the effects of parcelling of nitrogenous and potassic fertilization, in relation to corms, cormels and floral spikes production.

Theree were effects of parcelling fertilization on number and weight of corms, cormels and floral spikes. In general nitrogen influences more on number of corms and cormels while potassium influences on its weight.

\section{LITERATURA CITADA}

CATANI, R. A.; J. R. GALLO \& H. GARGANTINI. 1955 - Amostragem de Solos, Métodos de Análises, Interpretação e Indicações Gerais para Fins de Fertilidade. Bol. n. ${ }^{\circ}$ 69, Inst. Agron. de Campinas, Campinas, S. P.

DIEGO, J. S. 1973 - Los Gladíolos. Hojas Divulgadoras. Ministério de Agricultura. Madrid - España. pp. 12-15.

FERNANDES, P. D. 1972 - Cultura do Gladiolo. F. M. V. A. Jaboticabal, S. P. 15 pp. (mimeografado).

1974 - Alguns Estudos de Adrubação do Gladíolo. Tese de Doutorado apresentada à Escola Superior de Agricultura «Luiz de Queiroz», Piracicaba, S. P. 104 pp.

HAAG, H. P.; G. D. OLIVEIRA \& J. R. MATTOS. 1970 - Nutrição Mineral de Plantas Ornamentais. I. Absorção de Nutrientes pela Cultura de Gladiolos. Anais da E. S. A. «Luiz de Queiroz», XXVII : 125-41.

KENNETH, P. 1950 - Gladiolus. E: Florist Crop Production and Marketing, pp. 540-541. Cornell Univ. Ithaca. New York.

KRONE, P. R. 1951 - Gladiolus Soils and Fertilizers. The Gladiolus: 99-108. 
MALAVOLTA, E.; E. A. GRANER; T. COURY; M. O. C. BRASIL SOBRINHO \& J. A. C. PACHECO. 1955 - Studies on the Mineral Nutrition of Cassava (Manihot utilissima Pohl). Plant Physiology, $30: 81-2$.

McCleLLAN, W. D. 1954 - Fertilization Furhter Experiments with Fertilizers for Gladialus. The Gladiolus: 66-84.

PIMENTEL GOMES, F. 1970 - Curso de Estatística Experimental. E. S. A. \&Luiz de Queiroz», U. S. P. Piracicaba, S. P.

PUCCINELLI, L. F. R. \& P. D. FERNANDES. 1974 - Adubação Nitrogenada em Gladíolos. Fontes, Espécies de Aplicação e Localizações. Científica, I(1) : 24-33.

SOUZA, H. M. 1959 - A Cultura de Gladiolos. Inst. Agronômico Estado de São Paulo. Campinas, S. P. 16 pp.

ULRICH, A. \& K. OHKI. 1966 - Potassium. Em Diagnostic Criteria for Plants and Soils, pp. 362-393. (ed.) H. D. Chapmann, Univ. California, Div. Agric. Sci.

VAN DIEST, A. \& R. L. FLANNERY. 1963 - The Nutritive Requeriments of Gladiolus in New Jersey Soils. Proc. Amer. Soc. Hort. Sci. 82 : 494-503.

WATERS, W. E. 1965. Nutrient Requeriments of Gladiolus. Cormels on Sandy Soils of Florida. Proc. Soll Soc. Fla., $25: 59-63$.

WOLTZ, S. S. 1955 - Effect of Differential Supplies of Nitrogen, Potassium and Calcium on Quality and Yield of Gladiolus Flowers and Corms. Proc. Amer. Soc. Hort. Sci., 65 : 427-435. 